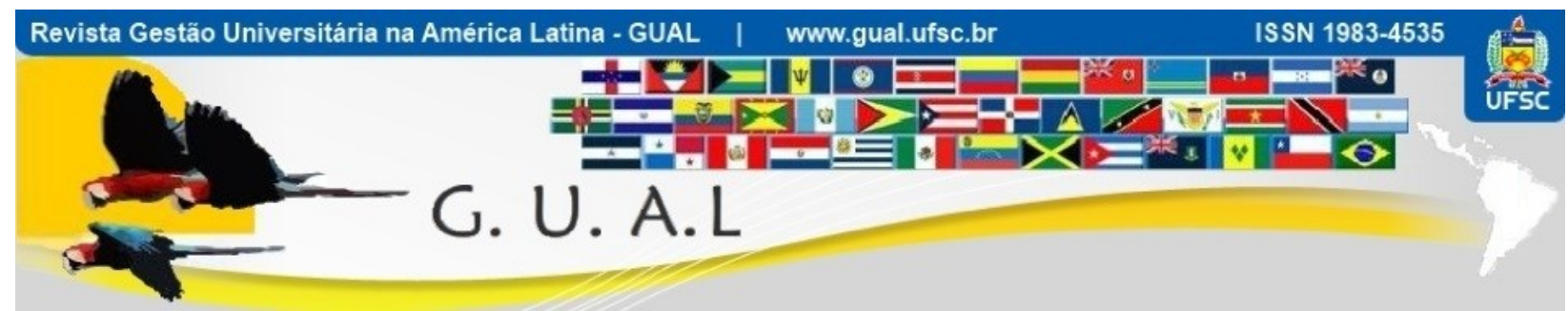

DOI: http://dx.doi.org/10.5007/1983-4535.2016v9n4p26

\title{
EDUCAÇÃO A DISTÂNCIA: UMA ANÁLISE ESTATÍSTICA DOS FATORES RELACIONADOS À EVASÃO E À PERMANÊNCIA
}

\section{DISTANCE EDUCATION: A STATISTICAL ANALYSIS OF FACTORS RELATED TO EVASION AND PERMANENCE}

Ricardo Antonio Cornelio, Mestre

Centro Universitario Una quimica01136@gmail.com

Fernanda Carla Wasner Vasconcelos, Doutora Centro Universitario Una fernanda.wasner@prof.una.br

Iris Barbosa Goulart, Doutora

Centro Universitario Una irisbgoulart@gmail.com

Recebido em 04/dezembro/2015

Aprovado em 14/outubro/2016

Sistema de Avaliação: Double Blind Review

Esta obra está sob uma Licença Creative Commons Atribuição-Uso. 


\title{
RESUMO
}

O maior desafio que as organizações enfrentam nos dias atuais está relacionado à adoção de medidas adequadas para lidar com a grande velocidade de inovação. A Educação a Distância (EaD), com a utilização das novas tecnologias de informação e comunicação (TICs), tem viabilizado o acesso a um número cada vez maior de sujeitos. Uma das vantagens frequentemente citada da $\mathrm{EaD}$ é permitir ao aluno estudar onde quer que esteja e quando lhe for mais conveniente. Junte-se a essa liberdade a utilização de computadores cada vez mais velozes e o desenvolvimento de novos aplicativos, propiciando o crescimento da educação a distância. Entretanto, essa expansão e o uso das tecnologias, por si só, não são capazes de evitar a ocorrência de evasão. Evitar o aumento da evasão e levantar as suas causas é atividade relevante para as instituições que tenham a capacidade de dar apoio aos estudantes durante o desenvolvimento de seu curso. Para identificar as questões que mais retratam as facilidades e dificuldades enfrentadas pelo alunado em cursos $\mathrm{EaD}$, optou-se pela técnica da Análise Fatorial Exploratória, aplicada em duas categorias de alunos, uma delas constituída pelos alunos matriculados e alunos formados e a outra categoria composta de alunos que abandonaram o curso em um polo de apoio presencial do município de Itabira - MG.

Palavras-chave: Educação a distância. Análise fatorial. Evasão. Permanência.

\begin{abstract}
The biggest challenge that the organizations face today is related to the adoption of appropriate measures to deal with the high speed of innovation. Distance Education, with the use of new information and communication technologies (ICT), has enabled access to a growing number of people. One of the frequently cited advantages of distance learning is to allow students to study wherever they are and at their most convenient time. Combining this freedom with the use of increasingly faster computers and the development of new apps, leads to the growth of distance education. However, this expansion and the use of technologies by itself are not able to prevent the occurrence of dropout. To avoid increasing evasion and investigate its causes is a relevant activity to the institutions that have the capacity to provide support to students during the development of its course. To identify the issues that most portray the facilities and difficulties faced by the students in distance education courses, we chose the Exploratory Factor Analysis technique, applied in two categories of students, one made up of the enrolled and graduated students and the other category composed by students who dropped out of the course in a presential support basis in the county of Itabira - MG.
\end{abstract}

Key words: Distance education. Factor analysis. Evasion. Permanence. 


\section{EDUCAÇÃO A DISTÂNCIA: UMA ANÁLISE ESTATÍSTICA DOS FATORES RELACIONADOS À

\section{INTRODUÇÃO}

Nas últimas décadas, a principal inovação na área da educação foi o desenvolvimento de sistemas tecnológicos de $\mathrm{EaD}$ com a finalidade de disseminar e promover oportunidades educacionais para um grande número de pessoas em tempos e locais diferentes, visando não somente melhoras quantitativas, mas principalmente a qualidade dos serviços ofertados.

De acordo com Costa et al. (2011, p. 1589), é necessário observar que, para ocorrer uma inserção destas novas tecnologias, devem acontecer mudanças curriculares nas instituições de ensino, com foco em uma aprendizagem significativa e no desenvolvimento de competências voltadas para o futuro profissional no mercado de trabalho.

Silva e Andriola (2012, p. 373) verificaram, em seus estudos, que a frequência de navegação e de pesquisa na Internet, bem como a utilização de softwares aplicativos, de ferramentas de comunicação e de participação em comunidades virtuais, realmente contribuem para o desenvolvimento do domínio tecnológico dos alunos de $\mathrm{EaD}$.

Para Garcia Sobreira et al. (2013, p. 417), a pesquisa em tecnologia não só inova, mas exige a inovação, convocando os pesquisadores e o público em geral a serem todos produtores de tecnologia e não apenas críticos do seu uso, visto que os processos de sua utilização estão sempre conjugados com novas demandas de desenvolvimento sugeridos pelos usuários, o que amplia o número de pessoas interessadas e com real capacidade de realizar inovações tecnológicas em campos antes considerados distantes.

$\mathrm{Na} \mathrm{EaD}$ há de se ressaltar o seu poder de alcance, sua abrangência e a sua capacidade de inserção dos indivíduos no universo da educação superior.

Nesse sentido, conforme assevera Ferrugini e Pinto (2014, p. 97), julga-se que o primeiro passo já foi dado para dinamizar essa modalidade de educação e identifica-se que a qualidade da $\mathrm{EaD}$ depende de uma série de processos e fatores que envolvem desde o planejamento da implantação do curso, passando por adequada seleção, qualificação e desenvolvimento de habilidades específicas dos profissionais envolvidos, além de controle e avaliação constante dos cursos.

Porém, o uso das tecnologias da informação e comunicação na educação a distância é, muitas vezes, apontado como o principal responsável da evasão escolar e das dificuldades de acesso às escolas, mas a tecnologia, apesar de sua importância, não deve ser encarada como o principal fator, conforme asseveram Salvucci, Lisboa e Mendes (2012, p. 50). 


\section{EDUCAÇÃO A DISTÂNCIA: UMA ANÁLISE ESTATÍSTICA DOS FATORES RELACIONADOS À \\ EVASÃO E À PERMANÊNCIA \\ DOI: http://dx.doi.org/10.5007/1983-4535.2016v9n4p26}

A evasão não deve ser vista como algo inevitável ou até inerente a tal modalidade de ensino-aprendizagem, mas como um problema inerente à gestão de cursos a distância. Cabe aos educadores e pesquisadores que lidam nessa esfera buscar identificar as causas e prevenir sua incidência para tentar reduzi-la (DE FÁTIMA BRUNO-FARIA; FRANCO, 2012, p. 46).

As causas da não permanência estudantil são múltiplas e correspondem tanto a variáveis internas à própria ação instrucional, quanto a elementos externos à mesma situação (UMEKAWA, 2014, p. 82).

Este estudo buscou abordar as tecnologias utilizadas em cursos de graduação e, de modo especial, a evasão/permanência em Educação a Distância dos alunos de graduação de um Polo de Apoio Presencial. A seguinte questão norteadora direciona a pesquisa: "Quais os fatores que mais impactam a evasão/permanência dos alunos e ex-alunos de Educação a Distância nos cursos de graduação de um Polo de Apoio Presencial do Município de Itabira MG, no período de agosto de 2009 a agosto de 2014?"

Com a finalidade de responder a este questionamento traçou-se como objetivo geral analisar os fatores que mais motivam as evasões/permanências em cursos na modalidade à distância e como objetivos específicos descrever o contexto de estudo do aluno no curso a distância e os potenciais elementos dificultadores/facilitadores de sua permanência; caracterizar as questões tecnológicas envolvidas na educação a distância; identificar os aspectos pessoais relacionados à evasão ou à permanência em cursos ofertados à distância e identificar os aspectos relacionados às condições do curso que mais influenciam a evasão ou a permanência em cursos ofertados à distância.

\section{A PESQUISA REALIZADA}

Para a classificação dessa pesquisa, tomou-se como base a taxonomia apresentada por Lakatos e Marconi (2010). Uma pesquisa quantitativa foi adotada.

Para estas autoras

a pesquisa [...] é um procedimento formal, com método de pensamento reflexivo, que requer um tratamento científico e se constitui no caminho para conhecer a realidade ou para descobrir verdades parciais (LAKATOS, MARCONI, 2010, p. 139).

Quanto aos fins, esta é uma pesquisa descritiva, pois busca descrever as percepções dos alunos e ex-alunos pesquisados. 
Quanto aos meios, é uma pesquisa de campo. A pesquisa é de campo, pois os dados foram coletados entre os alunos e ex-alunos de graduação de um Polo de Apoio Presencial (PAP) do município de Itabira (MG), no período compreendido entre agosto de 2009 a agosto de 2014. A população escolhida foi composta de 678 alunos de graduação.

Foi utilizada a ferramenta de elaboração de formulários denominada Google Docs ${ }^{\circledR}$, que disponibiliza os formulários através da internet para preenchimento pelos alunos e exalunos.

A coleta de dados foi realizada por meio do envio de e-mail aos 678 alunos e exalunos de graduação do polo no dia 25 de outubro de 2014, sendo utilizado um banco de dados com os endereços dos alunos pesquisados e do envio do questionário através do link: http://goo.gl/forms/b0q4EbdzoY. Em 26 de novembro de 2014, às 23h00, o período de pesquisa foi encerrado. Foram recebidos 342 questionários, equivalendo a quase $50 \%$ da amostra estudada, que contemplavam a escala dos fatores relacionados à permanência e à evasão em EaD, além das informações sociodemográficas.

Destes, 337 questionários estavam aptos por apresentar preenchimento integral, sendo, portanto, utilizados para as análises. Terminado o processo de coleta de dados, as informações foram enviadas para o SPSS (Statistical Package for the Social Science) versão 13.3 software que viabilizou as análises do material coletado.

Para o desenvolvimento da análise estatística procedeu-se inicialmente a tabulação dos dados do perfil da amostra em planilha eletrônica Microsoft Excel ${ }^{\circledR}$, em seguida foi analisada a ausência de dados, o que ocorreu nas questões referentes ao perfil dos candidatos. Quanto à identificação dos fatores que facilitam ou dificultam a permanência dos alunos, procedeu-se inicialmente à verificação da consistência interna do questionário.

Para identificar as questões que mais retratam as facilidades e dificuldades percebidas na amostra, optou-se pela técnica da Análise Fatorial Exploratória, aplicada em duas categorias de alunos, uma delas constituída pelos alunos matriculados e alunos formados e a outra categoria composta de alunos que abandonaram o curso.

A Análise Fatorial, segundo Hair et al. (2009, p. 92), é uma técnica de interdependência na qual todas as variáveis são simultaneamente consideradas, cada uma relacionada com todas as outras, e as variáveis estatísticas (fatores) são formadas para maximizar seu poder de explicação do conjunto inteiro de variáveis. Isto desvenda a estrutura 


\section{EDUCAÇÃO A DISTÂNCIA: UMA ANÁLISE ESTATÍSTICA DOS FATORES RELACIONADOS À \\ EVASÃO E À PERMANÊNCIA \\ DOI: http://dx.doi.org/10.5007/1983-4535.2016v9n4p26}

existente, mas que não é observável diretamente. As dimensões com variabilidade comum formam os chamados fatores.

Para a utilização da Análise Fatorial foram verificadas as condições para a sua aplicação: o número de dados da amostra e o Teste de Esfericidade de Bartlett conforme afirma Hair et al. (2005, p. 98), fornece a probabilidade estatística de que a matriz de correlação tenha correlações significantes entre pelo menos algumas variáveis e para que o método de análise fatorial seja adequado, o valor da significância do Teste de Bartlett deve ser menor que 0,05 .

Segundo Corrar (2007, p. 118), o método de componentes principais utilizado para extração de fatores não possui a restrição de normalidade multivariada.

Quanto à identificação da Confiabilidade, segundo Hair et al. (2005, p. 111), "uma das medidas de confiabilidade, mais comumente usada é a consistência interna, a qual avalia a consistência entre variáveis de uma escala múltipla, que é o Alpha de Cronbach que admite no mínimo Alpha igual a 0,60”. Nesse estudo obteve-se Alpha de Cronbach igual a 0,925 para os alunos matriculados e formados e 0,953 para os alunos evadidos. Estes resultados apontaram para uma excelente consistência interna deste instrumento de medida.

\section{ANÁLISE DOS RESULTADOS}

Realizou-se, inicialmente, a análise das médias dos fatores dos alunos matriculados e os já formados, conforme apresentado na Tabela 1. Estas médias de pontuação referem-se à média de pontos atribuída no intervalo de 1 a 5 , em que a pontuação igual a 1 refere-se à pouca facilidade e a pontuação 5 à muita facilidade, observada no quesito atribuído à persistência em $\mathrm{EaD}$.

Nota-se que as questões que apresentaram as maiores médias, retratando assim as questões que mais facilitam a permanência durante a realização do curso, foram as questões 13 - O acesso ao material didático utilizado no curso (4,36); questão 07 - Apoio da instituição de ensino frente às dificuldades tecnológicas encontradas por mim durante a realização do curso $(4,15)$ e a questão 09 - O acesso ao sistema virtual do curso $(4,14)$ para os alunos matriculados. 
Tabela 1 Média dos fatores relacionados à persistência em EaD.

\begin{tabular}{|c|c|c|}
\hline \multirow{3}{*}{ Fatores } & \multicolumn{2}{|c|}{ Situação acadêmica } \\
\hline & $\begin{array}{l}\text { Aluno } \\
\text { matriculado }\end{array}$ & $\begin{array}{l}\text { Aluno } \\
\text { formado }\end{array}$ \\
\hline & Média & Média \\
\hline [01 - O apoio fornecido pelo tutor e interação entre os participantes do curso.] & 3,97 & 3,62 \\
\hline [02 - Minha habilidade em administrar o tempo para me dedicar aos estudos.] & 3,56 & 3,98 \\
\hline [03 - A duração total do curso.] & 4,02 & 4,25 \\
\hline $\begin{array}{l}\text { [04 - Alterações em minha rotina de trabalho ocorridas durante a realização } \\
\text { curso.] }\end{array}$ & 3,44 & 3,64 \\
\hline [05 - O grau de complexidade do curso.] & 3,54 & 3,55 \\
\hline [06 - A qualidade gramatical das mensagens trocadas pelo tutor com os alunos.] & 4,03 & 3,72 \\
\hline $\begin{array}{l}\text { [07 - Apoio da instituição de ensino frente às dificuldades tecnológicas encontra } \\
\text { por mim durante a realização do curso.] }\end{array}$ & 4,15 & 3,94 \\
\hline [08 - Minha habilidade de conciliar o curso com outras atividades pessoais.] & 3,78 & 3,98 \\
\hline [09 - O acesso ao sistema virtual do curso. $]$ & 4,14 & 4,38 \\
\hline $\begin{array}{l}\text { [10 - Minha habilidade de elaborar um plano de estudo que oriente min } \\
\text { atividades.] }\end{array}$ & 3,61 & 3,83 \\
\hline [11 - O vínculo estabelecido entre tutor e alunos.] & 4,01 & 3,77 \\
\hline [12 - Eventos familiares durante a realização do curso.] & 3,51 & 3,49 \\
\hline [13 - O acesso ao material didático utilizado no curso.] & 4,36 & 4,28 \\
\hline $\begin{array}{l}\text { [14 - A qualidade do feedback/orientações fornecidos pelo tutor em relação } \\
\text { minhas participações.] }\end{array}$ & 4,03 & 3,87 \\
\hline [15 - O incentivo familiar para a realização do curso.] & 4,14 & 4,11 \\
\hline [16 - Minha habilidade em utilizar recursos e ferramentas tecnológicas do curso.] & 4,01 & 4,36 \\
\hline [17 - Acesso às informações do curso antes do seu início.] & 4,03 & 4,08 \\
\hline [18 - Quantidade de atividades propostas durante o curso.] & 3,94 & 3,92 \\
\hline [19 - Condições do ambiente de estudo em casa.] & 3,78 & 4,15 \\
\hline [20 - O grau de dificuldade das atividades propostas pelo curso.] & 3,56 & 3,72 \\
\hline
\end{tabular}

Fonte: Dados da Pesquisa.

Para os alunos que já formaram foram as questões 09 - $\mathrm{O}$ acesso ao sistema virtual do curso (4,38), 16 - Minha habilidade em utilizar recursos e ferramentas tecnológicas do curso $(4,36)$ e 13 - O acesso ao material didático utilizado no curso $(4,28)$.

Com relação à permanência:

É possível, criar um modelo sintético composto por três dimensões principais, que envolvem as questões pessoais, ou endógenas ao aluno, as questões acadêmicas ou exógenas ao aluno e as questões contextuais, relacionadas ao que envolve tanto o aluno quanto o curso (FIUZA; SARRIEIRA, 2013, p. 900).

Estas dimensões englobariam as variáveis obtidas no presente estudo, tanto para os alunos matriculados e/ou formados, que, segundo Umekawa (2014, p.150), a persistência em educação a distância sugere a possibilidade de que os participantes de ações educacionais ministradas à distância estejam sujeitos a diversas variáveis externas e/ou endógenas a eles mesmos que influenciem a decisão de permanecerem ou não no curso. 


\section{EDUCAÇÃO A DISTÂNCIA: UMA ANÁLISE ESTATÍSTICA DOS FATORES RELACIONADOS À \\ EVASÃO E À PERMANÊNCIA \\ DOI: http://dx.doi.org/10.5007/1983-4535.2016v9n4p26}

Verifica-se na Tabela 1 que esses fatores endógenos apresentam valores diferentes tanto para alunos matriculados quanto para alunos formados conforme visto nas questões: 02 - Minha habilidade em administrar o tempo para me dedicar aos estudos $(3,56$ e 3,98), 04 Alterações em minha rotina de trabalho ocorridas durante a realização do curso $(3,44$ e 3,64), 08 - Minha habilidade de conciliar o curso com outras atividades pessoais $(3,78$ e 3,98), 10 Minha habilidade de elaborar um plano de estudo que oriente minhas atividades $(3,61$ e 3,83), 12 - Eventos familiares durante a realização do curso $(3,51$ e 3,49), 15 - O incentivo familiar para a realização do curso $(4,14$ e 4,11), 16 - Minha habilidade em utilizar recursos e ferramentas tecnológicas do curso $(4,01$ e 4,36) e 19 - Condições do ambiente de estudo em casa $(3,78$ e 4,15) com predominância para os alunos formados que apresentaram maiores médias nestes fatores, com exceção para as questões 12 e 15.

Quanto às questões acadêmicas ou exógenas ao aluno, observa-se que os valores das médias para os alunos matriculados e formados apresentam-se diferentes, com exceção das questões 05 - O grau de complexidade do curso $(3,54$ e 3,55) e 18 - Quantidade de atividades propostas durante o curso $(3,94$ e 3,92$)$, cujos valores foram muito próximos. Os outros valores encontrados para esta dimensão foram: 01 - O apoio fornecido pelo tutor e interação entre os participantes do curso $(3,97$ e 3,62), 06 - A qualidade gramatical das mensagens trocadas pelo tutor com os alunos $(4,03$ e 3,72), 07 - Apoio da instituição de ensino frente às dificuldades tecnológicas encontradas por mim durante a realização do curso $(4,15$ e 3,94), 11 - O vínculo estabelecido entre tutor e alunos (4,01 e 3,77), 14 - A qualidade do feedback/orientações fornecidos pelo tutor em relação às minhas participações $(4,03$ e 3,87), e 20 - O grau de dificuldade das atividades propostas pelo curso (3,56 e 3,72), com predominância para os alunos matriculados que apresentaram maiores médias nestes fatores, com exceção para a questão 20 .

Relativo às questões contextuais, as médias dos alunos matriculados e dos alunos formados apresentam valores diferentes tanto para alunos matriculados quanto para alunos formados, conforme visto nas questões: 03 - A duração total do curso $(4,02$ e 4,25), 09 - O acesso ao sistema virtual do curso (4,14 e 4,38), 13 - $\mathrm{O}$ acesso ao material didático utilizado no curso $(4,36$ e 4,28) e 17 - Acesso às informações do curso antes do seu início (4,03 e 4,08), com predominância para os alunos formados que apresentaram maiores médias nestes fatores, com exceção para a questão 13 . 


\section{EDUCAÇÃO A DISTÂNCIA: UMA ANÁLISE ESTATÍSTICA DOS FATORES RELACIONADOS À \\ DOI: http://dx.doi.org/10.5007/1983-4535.2016v9n4p26}

A seguir, realizou-se a análise das médias dos fatores dos alunos que abandonaram o curso. Para a avaliação dos fatores relacionados à evasão em $\mathrm{EaD}$, foram perguntados os mesmos fatores para os alunos matriculados e os que já se formaram. O que mudou foi a consideração da pergunta, que neste caso avalia o grau de dificuldade percebido pelo aluno, atribuindo a escala 1 (um) para "Pouca dificuldade" e 5 (cinco) para "Muita dificuldade". Na Tabela 2, estão apresentadas as médias das pontuações indicadas na amostra de alunos evadidos.

Tabela 2 Média dos fatores relacionados à evasão em EaD.

\begin{tabular}{|c|c|}
\hline Fatores & $\begin{array}{c}\text { Grau de } \\
\text { dificuldade }\end{array}$ \\
\hline [01 - O apoio fornecido pelo tutor e interação entre os participantes do curso.] & 3,50 \\
\hline [02 - Minha habilidade em administrar o tempo para me dedicar aos estudos.] & 3,38 \\
\hline [03 - A duração total do curso.] & 3,43 \\
\hline [04 - Alterações em minha rotina de trabalho ocorridas durante a realização do curso.] & 3,41 \\
\hline [05 - O grau de complexidade do curso.] & 3,35 \\
\hline [06 - A qualidade gramatical das mensagens trocadas pelo tutor com os alunos.] & 3,45 \\
\hline $\begin{array}{l}\text { [07 - Apoio da instituição de ensino frente às dificuldades tecnológicas encontradas } \\
\text { durante a realização do curso.] }\end{array}$ & 3,63 \\
\hline [08 - Minha habilidade de conciliar o curso com outras atividades pessoais.] & 3,60 \\
\hline [09 - O acesso ao sistema virtual do curso.] & 3,69 \\
\hline [10 - Minha habilidade de elaborar um plano de estudo que oriente minhas atividades.] & 3,47 \\
\hline [11 - O vínculo estabelecido entre tutor e alunos.] & 3,53 \\
\hline [12 - Eventos familiares durante a realização do curso.] & 3,18 \\
\hline [13 - O acesso ao material didático utilizado no curso.] & 3,70 \\
\hline $\begin{array}{l}\text { [14 - A qualidade do feedback/orientações fornecidos pelo tutor em relação } \\
\text { participações.] }\end{array}$ & 3,64 \\
\hline [15 - O incentivo familiar para a realização do curso.] & 3,67 \\
\hline [16 - Minha habilidade em utilizar recursos e ferramentas tecnológicas do curso.] & 3,60 \\
\hline [17 - Acesso às informações do curso antes do seu início.] & 3,52 \\
\hline [18 - Quantidade de atividades propostas durante o curso.] & 3,53 \\
\hline [19 - Condições do ambiente de estudo em casa.] & 3,49 \\
\hline [20 - O grau de dificuldade das atividades propostas pelo curso.] & 3,48 \\
\hline
\end{tabular}

Fonte: Dados da pesquisa.

As questões que apresentaram as maiores médias, o que neste caso retratam as maiores dificuldades percebidas pelos alunos que abandonaram o curso, foram as questões $\mathbf{1 3}$ - $\mathrm{O}$ acesso ao material didático utilizado no curso $(3,7) ; 09$ - $\mathrm{O}$ acesso ao sistema virtual do curso $(3,69) ; 15$ - O incentivo familiar para a realização do curso $(3,67)$ e 14 - A qualidade do feedback/orientações fornecidos pelo tutor em relação às minhas participações $(3,64)$.

A literatura aponta diversos fatores que podem levar o aluno à evasão: quanto ao acesso ao material didático, Almeida et al. (2013) classificam, como categoria-síntese, problemas com a tecnologia, enquanto que Umekawa (2014) se reporta ao fator tecnológico e às questões referentes à tutoria. Com referência ao acesso ao sistema virtual do curso, Abbad, 


\section{EDUCAÇÃO A DISTÂNCIA: UMA ANÁLISE ESTATÍSTICA DOS FATORES RELACIONADOS À

Carvalho e Zerbini (2006) afirmaram que participantes com pouco acesso aos recursos eletrônicos do curso, como chat, mural e outros, foram aqueles que tenderam a abandonar o curso, e Fernandes et al. (2010) apontaram que os principais indicadores da evasão que exigem maior atenção por parte dos gestores do curso à distância estão relacionados diretamente às variáveis: acesso do aluno ao ambiente virtual de aprendizagem (AVA).

O incentivo familiar para a realização do curso é referenciado em Almeida et al. (2013) e Umekawa (2014). Finalmente, a qualidade do feedback/orientações fornecidos pelo tutor em relação às minhas participações, Almeida et al. (2013) relatam a falta de Apoio Acadêmico (falta de interação entre o professor-tutor e os alunos, tais como falhas de comunicação com o tutor e falta de feedback do tutor) e Umekava (2014) avalia o quanto aspectos relacionados às competências demonstradas pelo tutor, ao longo do curso, influenciam na evasão.

Com o objetivo de identificar os fatores que mais impactam a evasão/permanência dos alunos e ex-alunos, fez-se a análise os dois grupos de respondentes: o primeiro grupo foi constituído pelos alunos matriculados e alunos formados versus o segundo grupo composto pelos alunos evadidos, aplicando-se em cada grupo de respostas a Análise Fatorial Exploratória, obtendo-se as componentes de maior relevância nesta amostra.

No primeiro grupo de respondentes foram obtidos os seguintes resultados da Análise Fatorial: o Teste de KMO foi 0,909 e Teste de Bartlett apresentou um nível de significância de 0,000. Os valores de KMO (Kaiser-Meyer-Olkin) e de Esferecidade de Bartlett permitem a aplicação da Análise Fatorial para as variáveis desse estudo.

Outro conceito que deve ser observado é o das Comunalidades que, segundo Corrar (2007, p. 90) representam o percentual de explicação que uma variável obteve pela Análise Fatorial, isto é, quanto todos os fatores juntos são capazes de explicar uma variável. Quando o valor das Comunalidades, Tabela 3, estiver mais próximo de 1, maior é o poder de explicação dos fatores. Foi usado o método de extração por componentes principais que favoreceu a construção da matriz de componentes para os alunos matriculados e alunos formados.

Os valores menores das Comunalidades ocorrem na questão 12 - Eventos familiares durante a realização do curso $(0,457)$ e na questão 13 - O acesso ao material didático utilizado no curso $(0,409)$ as quais foram mantidas na análise, pois de acordo com os estudos de Umekawa (2014), principal referência deste estudo, estes fatores apresentaram resultados significativos $(0,62$ e 0,66$)$ respectivamente, para as mesmas questões presentes neste estudo. 
Tabela 3 Comunalidades do grupo de alunos matriculados e os que já formaram.

\begin{tabular}{|c|c|c|}
\hline Variáveis & Inicial & Extração \\
\hline [01 - O apoio fornecido pelo tutor e interação entre os participantes do curso.] & 1,000 & ,760 \\
\hline [02 - Minha habilidade em administrar o tempo para me dedicar aos estudos.] & 1,000 & 658 \\
\hline [03 - A duração total do curso.] & 1,000 & 686 \\
\hline [04 - Alterações em minha rotina de trabalho ocorridas durante a realização do curso.] & 1,000 & ,508 \\
\hline [05 - O grau de complexidade do curso.] & 1,000 & ,704 \\
\hline [06 - A qualidade gramatical das mensagens trocadas pelo tutor com os alunos.] & 1,000 & ,715 \\
\hline $\begin{array}{l}\text { [07 - Apoio da instituição de ensino frente às dificuldades tecnológicas encontradas por } \\
\text { mim durante a realizacão do curso.] }\end{array}$ & 1.000 & 635 \\
\hline [08 - Minha habilidade de conciliar o curso com outras atividades pessoais.] & 1,000 & ,633 \\
\hline [09 - O acesso ao sistema virtual do curso.] & 1,000 &, 510 \\
\hline [10 - Minha habilidade de elaborar um plano de estudo que oriente minhas atividades.] & 1,000 & ,718 \\
\hline [11 - O vínculo estabelecido entre tutor e alunos.] & 1,000 & 616 \\
\hline [12 - Eventos familiares durante a realização do curso.] & 1,000 & 457 \\
\hline [13 - O acesso ao material didático utilizado no curso.] & 1,000 & ,409 \\
\hline $\begin{array}{l}\text { [14 - A qualidade do feedback/orientações fornecidos pelo tutor em relação às minhas } \\
\text { participações.] }\end{array}$ & 1,000 & 680 \\
\hline [15 - O incentivo familiar para a realização do curso.] & 1,000 & ,617 \\
\hline [16 - Minha habilidade em utilizar recursos e ferramentas tecnológicas do curso.] & 1,000 & 605 \\
\hline [17 - Acesso às informações do curso antes do seu início.] & 1,000 & 627 \\
\hline [18 - Quantidade de atividades propostas durante o curso.] & 1,000 &, 554 \\
\hline [19 - Condições do ambiente de estudo em casa.] & 1,000 & 659 \\
\hline [20 - O grau de dificuldade das atividades propostas pelo curso.] & 1,000 & ,561 \\
\hline
\end{tabular}

Fonte: Dados da Pesquisa.

Nota: Método de extração: análise do componente principal.

A extração inicial dos fatores ocorreu por meio da análise dos componentes principais. A Tabela 4 propõe a análise dos componentes principais e indica uma estrutura com 4 componentes que explicam, em conjunto, $61,56 \%$ da variância total dos dados.

Tabela 4 Variância Total Explicada.

\begin{tabular}{l|c|c|c|c|c|c|c|c|c}
\hline \multirow{2}{*}{ Componente } & \multicolumn{3}{|c|}{ Valores próprios iniciais } & \multicolumn{3}{c|}{$\begin{array}{c}\text { Somas de extração de } \\
\text { carregamentos ao quadrado }\end{array}$} & \multicolumn{3}{c}{$\begin{array}{c}\text { Somas rotativas de carregamentos } \\
\text { ao quadrado }\end{array}$} \\
\cline { 2 - 10 } & Total & $\begin{array}{c}\% \text { de } \\
\text { variância }\end{array}$ & $\begin{array}{c}\% \\
\text { cumulativa }\end{array}$ & Total & $\begin{array}{c}\% \text { de } \\
\text { variância }\end{array}$ & $\begin{array}{c}\% \\
\text { cumulativ } \\
\text { a }\end{array}$ & Total & $\begin{array}{c}\% \text { de } \\
\text { variância }\end{array}$ & $\begin{array}{c}\% \\
\text { cumulativa }\end{array}$ \\
\hline 1 & 8,347 & 41,734 & 41,734 & 8,347 & 41,734 & 41,734 & 4,171 & 20,856 & 20,856 \\
2 & 1,783 & 8,914 & 50,648 & 1,783 & 8,914 & 50,648 & 3,816 & 19,081 & 39,937 \\
3 & 1,120 & 5,602 & 56,250 & 1,120 & 5,602 & 56,250 & 2,881 & 14,404 & 54,341 \\
4 & 1,062 & 5,310 & 61,560 & 1,062 & 5,310 & 61,560 & 1,444 & 7,218 & 61,560 \\
\hline
\end{tabular}

Fonte: Dados da Pesquisa.

Nota: Método de extração: análise do componente principal.

Em seguida, na Tabela 5, estão distribuídos os componentes principais, formando os fatores ou grupos de interpretação, cuja classificação apresentou as maiores facilidades, evidenciadas pelos alunos matriculados e os alunos que já se formaram: a primeira componente, composta de oito questões, retrata a (disciplina e habilidades gerais do aluno) 


\section{EDUCAÇÃO A DISTÂNCIA: UMA ANÁLISE ESTATÍSTICA DOS FATORES RELACIONADOS À \\ EVASÃO E À PERMANÊNCIA \\ DOI: http://dx.doi.org/10.5007/1983-4535.2016v9n4p26}

+ (desenho do curso); segunda componente, composta de 06 (seis) questões, retrata o (desempenho da tutoria) + (apoio institucional); terceira componente, composta de 05(cinco) questões, retrata o (ambiente próprio) + (atividades do curso) e a quarta componente, representada por apenas 1 questão, retrata a (complexidade do curso).

Obtêm-se, ainda da Tabela 5 , as três principais variáveis que facilitaram a permanência dos alunos matriculados e alunos formados representados pelas questões: 10 Minha habilidade de elaborar um plano de estudo que oriente minhas atividades $(0,797), \mathbf{0 2}$ Minha habilidade em administrar o tempo para me dedicar aos estudos $(0,760)$ e $\mathbf{0 8}$ - Minha habilidade de conciliar o curso com outras atividades pessoais $(0,731)$ na primeira componente; na segunda componente têm-se as questões: 07 - Apoio da instituição de ensino frente às dificuldades tecnológicas encontradas por mim durante a realização do curso $(0,735), \mathbf{1 4}$ - A qualidade do feedback/orientações fornecidos pelo tutor em relação às minhas participações $(0,722)$ e $\mathbf{0 1}$ - O apoio fornecido pelo tutor e interação entre os participantes do curso $(0,718)$; na terceira componente têm-se as questões: 15 - O incentivo familiar para a realização do curso $(0,735), \mathbf{1 9}$ - Condições do ambiente de estudo em casa $(0,639)$ e $\mathbf{1 8}$ Quantidade de atividades propostas durante o curso $(0,562)$ e na quarta componente com a questão 05 - $\mathrm{O}$ grau de complexidade do curso $(0,687)$.

Tabela 5 Matriz de componente rotativa - alunos matriculados e os já formados.

\begin{tabular}{|c|c|c|c|c|c|}
\hline \multirow{2}{*}{ QUESTÕES } & \multicolumn{4}{|c|}{ COMPONENTE } & \multirow{2}{*}{$\begin{array}{l}\text { FATORES } \\
\text { FACILITADORES }\end{array}$} \\
\hline & 1 & 2 & 3 & 4 & \\
\hline $\begin{array}{l}\text { [10 - Minha habilidade de elaborar um plano de estudo } \\
\text { que oriente minhas atividades.] }\end{array}$ & ,797 &, 116 &, 174 & ,200 & \multirow{8}{*}{ 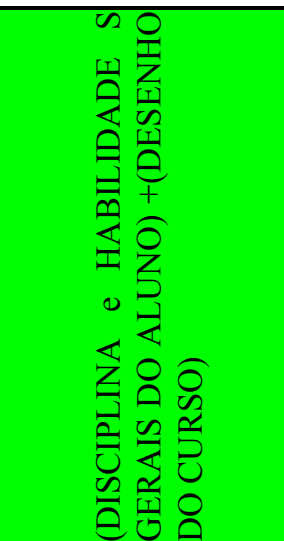 } \\
\hline $\begin{array}{l}\text { [02 - Minha habilidade em administrar o tempo para me } \\
\text { dedicar aos estudos.] }\end{array}$ & ,760 &, 133 & ,223 &, 112 & \\
\hline $\begin{array}{l}\text { [08 - Minha habilidade de conciliar o curso com outras } \\
\text { atividades pessoais.] }\end{array}$ &, 731 & --- & ,304 & --- & \\
\hline [03 - A duração total do curso.] & ,718 & ,398 & ,102 & --- & \\
\hline $\begin{array}{l}\text { [16 - Minha habilidade em utilizar recursos e ferramentas } \\
\text { tecnológicas do curso.] }\end{array}$ & ,594 & ,221 & ,363 &,- 266 & \\
\hline $\begin{array}{l}\text { [04 - Alterações em minha rotina de trabalho ocorridas } \\
\text { durante a realização do curso.] }\end{array}$ &, 537 & ,202 & ,275 & ,321 & \\
\hline [09 - O acesso ao sistema virtual do curso.] &, 521 & ,482 & --- & --- & \\
\hline [13 - O acesso ao material didático utilizado no curso.] & ,412 & ,378 & ,178 & 255 & \\
\hline \multicolumn{5}{|l|}{ [07 - Apoio da instituição de ensino frente às dificuldades } & \multirow{5}{*}{ 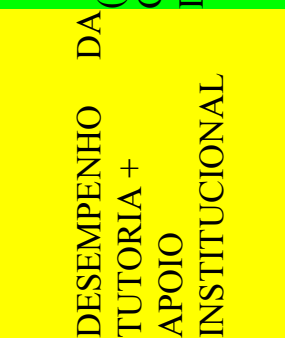 } \\
\hline $\begin{array}{l}\text { tecnológicas encontradas por mim durante a realização do } \\
\text { curso.] }\end{array}$ & ,308 & ,735 & --- & --- & \\
\hline $\begin{array}{l}\text { [14 - A qualidade do feedback/orientações fornecidos } \\
\text { pelo tutor em relação às minhas participações.] }\end{array}$ & --- & ,722 & ,396 & & \\
\hline $\begin{array}{l}\text { [01 - O apoio fornecido pelo tutor e interação entre os } \\
\text { participantes do curso.] }\end{array}$ & --- & ,718 &, 104 & ,473 & \\
\hline [11 - O vínculo estabelecido entre tutor e alunos.] & 175 & ,706 & ,273 & 116 & \\
\hline
\end{tabular}




\section{EDUCAÇÃO A DISTÂNCIA: UMA ANÁLISE ESTATÍSTICA DOS FATORES RELACIONADOS À \\ EVASÃO E À PERMANÊNCIA \\ DOI: http://dx.doi.org/10.5007/1983-4535.2016v9n4p26}

\begin{tabular}{|c|c|c|c|c|c|}
\hline $\begin{array}{l}\text { [06 - A qualidade gramatical das mensagens trocadas pelo } \\
\text { tutor com os alunos.] }\end{array}$ &, 191 & ,671 & ,282 & ,387 & \\
\hline [17 - Acesso às informações do curso antes do seu início.] & 219 & ,536 & ,407 &,- 355 & \\
\hline [15 - O incentivo familiar para a realização do curso.] & --- &, 133 & ,735 & ,223 & 8 \\
\hline [19 - Condições do ambiente de estudo em casa.] & ,404 & 203 & 639 & 214 & \\
\hline $\begin{array}{l}{[18 \text { - Quantidade de atividades propostas durante o }} \\
\text { curso.] }\end{array}$ & ,276 & ,402 &, 562 & --- & 峲。嵌 \\
\hline [12 - Eventos familiares durante a realização do curso.] & 296 & ,236 &, 556 & --- & 四园。 \\
\hline $\begin{array}{l}\text { [20 - O grau de dificuldade das atividades propostas pelo } \\
\text { curso.] }\end{array}$ & ,427 &, 128 &, 554 & ,237 & 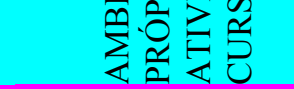 \\
\hline [05 - O grau de complexidade do curso.] & ,299 & ,238 & ,292 & ,687 & COMPLEXIDADE \\
\hline
\end{tabular}

Fonte: Dados da pesquisa.

Nota: Método de extração: Análise do Componente principal.

Método de rotação: Varimax com normalização de Kaiser.

a. Rotação convergida em 10 iterações.

No segundo grupo de respondentes foram obtidos os seguintes resultados da Análise Fatorial: o Teste de KMO foi 0,924 e Teste de Bartlett apresentou um nível de significância de 0,000 . A Tabela 6 apresenta os valores das Comunalidades para este grupo.

Tabela 6 Comunalidades - alunos evadidos.

\begin{tabular}{|c|c|c|}
\hline Questões & Inicial & Extração \\
\hline [01 - O apoio fornecido pelo tutor e interação entre os participantes do curso.] & 1,000 &, 750 \\
\hline [02 - Minha habilidade em administrar o tempo para me dedicar aos estudos.] & 1,000 & ,727 \\
\hline [03 - A duração total do curso.] & 1,000 &, 636 \\
\hline [04 - Alterações em minha rotina de trabalho ocorridas durante a realização do curso.] & 1,000 & 660 \\
\hline [05 - O grau de complexidade do curso.] & 1,000 & ,533 \\
\hline [06 - A qualidade gramatical das mensagens trocadas pelo tutor com os alunos.] & 1,000 & ,593 \\
\hline [07 - Apoio da instituição de ensino frente às dificuldades tecnológicas encontradas $p$ & & \\
\hline mim durante a realização do curso.] & 1,000 & 697 \\
\hline [08 - Minha habilidade de conciliar o curso com outras atividades pessoais.] & 1,000 & ,741 \\
\hline [09 - O acesso ao sistema virtual do curso. $]$ & 1,000 & ,724 \\
\hline [10 - Minha habilidade de elaborar um plano de estudo que oriente minhas atividades.] & 1,000 & 665 \\
\hline [11 - O vínculo estabelecido entre tutor e alunos.] & 1,000 & ,716 \\
\hline [12 - Eventos familiares durante a realização do curso.] & 1,000 & ,484 \\
\hline [13 - O acesso ao material didático utilizado no curso.] & 1,000 & ,761 \\
\hline $\begin{array}{l}\text { [14 - A qualidade do feedback/orientações fornecidos pelo tutor em relação às minh } \\
\text { participacões. }\end{array}$ & 1.000 & .738 \\
\hline [15 - O incentivo familiar para a realização do curso.] & 1,000 & 600 \\
\hline [16 - Minha habilidade em utilizar recursos e ferramentas tecnológicas do curso.] & 1,000 & ,729 \\
\hline [17 - Acesso às informações do curso antes do seu início.] & 1,000 & ,738 \\
\hline [18 - Quantidade de atividades propostas durante o curso.] & 1,000 & ,582 \\
\hline [19 - Condições do ambiente de estudo em casa.] & 1,000 & ,737 \\
\hline [20 - O grau de dificuldade das atividades propostas pelo curso.] & 1,000 & 643 \\
\hline
\end{tabular}

Fonte: Dados da pesquisa.

Nota: Método de extração: análise do componente principal.

A questão 12 - Eventos familiares durante a realização do curso apresentou um valor de Comunalidade de 0,484, considerado baixo. Entretanto, esta questão foi mantida na 


\section{EDUCAÇÃO A DISTÂNCIA: UMA ANÁLISE ESTATÍSTICA DOS FATORES RELACIONADOS À \\ EVASÃO E À PERMANÊNCIA \\ DOI: http://dx.doi.org/10.5007/1983-4535.2016v9n4p26}

análise, pois de acordo com os estudos de Umekawa (2014), principal referência deste estudo, este fator apresentou resultado significativo $(0,62)$ e sugere que há possível interferência no processo de evasão dos alunos nos diferentes cursos.

A análise dos componentes principais indica uma estrutura com 3 componentes que explicam, em conjunto, $67,27 \%$ da variância total dos dados conforme descrito na Tabela 7 .

Tabela 7 Variância Total Explicada - grupo de alunos evadidos.

\begin{tabular}{|c|c|c|c|c|c|c|c|c|c|}
\hline \multirow{2}{*}{ 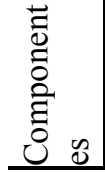 } & \multicolumn{3}{|c|}{ Valores próprios iniciais } & \multicolumn{3}{|c|}{$\begin{array}{c}\text { Somas de extração de } \\
\text { carregamentos ao quadrado }\end{array}$} & \multicolumn{3}{|c|}{$\begin{array}{c}\text { Somas rotativas de } \\
\text { carregamentos ao quadrado }\end{array}$} \\
\hline & Total & $\begin{array}{c}\% \text { de } \\
\text { variância } \\
\end{array}$ & $\begin{array}{c}\% \\
\text { cumulativa } \\
\end{array}$ & Total & $\begin{array}{c}\% \text { de } \\
\text { variância }\end{array}$ & $\begin{array}{c}\% \\
\text { cumulativa } \\
\end{array}$ & Total & $\begin{array}{c}\% \text { de } \\
\text { variância }\end{array}$ & $\begin{array}{c}\% \\
\text { cumulativa } \\
\end{array}$ \\
\hline 1 & 10,706 & 53,528 & & 10,706 & 53,528 & 53,528 & 4,817 & 24,085 & 24,085 \\
\hline 2 & 1,694 & & & 1,694 & & & 4,452 & 22,260 & 46,346 \\
\hline 3 & 1,055 & 5,275 & 67,274 & 1,055 & 5,275 & 67,274 & 4,186 & 20,928 & 67,274 \\
\hline
\end{tabular}

Fonte: Dados da pesquisa.

Nota: Método de extração: análise do componente principal.

Em seguida, na Tabela 8, estão distribuídos os componentes principais, formando os fatores ou grupos de interpretação, cuja classificação apresentou maiores dificuldades evidenciadas pelos alunos evadidos: a primeira componente é formada de oito questões, retrata o (desenho do curso $)+($ ambiente próprio $)+$ (habilidades tecnológicas $)+$ (atividades do curso); a segunda componente, composta de 06 (seis) questões, retrata o (desempenho da tutoria) + (apoio institucional) e a terceira componente, composta de 06 (seis) questões, retrata a (disciplina) + (habilidades gerais do aluno $)+($ complexidade do curso).

Obtêm-se, ainda, da Tabela 8 , as três principais variáveis que dificultaram a permanência dos alunos evadidos representados pelas questões: $\mathbf{1 3}$ - $\mathrm{O}$ acesso ao material didático utilizado no curso (0,718), 17 - Acesso às informações do curso antes do seu início $(0,705)$ e 09 - O acesso ao sistema virtual do curso $(0,702)$ na primeira componente; na segunda componente têm-se as questões: 01 - O apoio fornecido pelo tutor e interação entre os participantes do curso $(0,812), \mathbf{1 4}$ - A qualidade do feedback/orientações fornecidos pelo tutor em relação às minhas participações $(0,804)$ e $\mathbf{1 1}$ - $\mathrm{O}$ vínculo estabelecido entre tutor e alunos $(0,754)$ e na terceira componente têm-se as questões: 04 - Alterações em minha rotina de trabalho ocorridas durante a realização do curso $(0,796), 08$ - Minha habilidade de conciliar o curso com outras atividades pessoais $(0,784)$ e $\mathbf{0 2}$ - Minha habilidade em administrar o tempo para me dedicar aos estudos $(0,764)$. 


\section{EDUCAÇÃO A DISTÂNCIA: UMA ANÁLISE ESTATÍSTICA DOS FATORES RELACIONADOS À \\ EVASÃO E À PERMANÊNCIA}

DOI: http://dx.doi.org/10.5007/1983-4535.2016v9n4p26

Tabela 8 Matriz de componente rotativa - alunos evadidos.

\begin{tabular}{|c|c|c|c|c|}
\hline \multirow{2}{*}{ Questões } & \multicolumn{3}{|c|}{ Componente } & \multirow{2}{*}{$\begin{array}{c}\text { FATORES } \\
\text { DIFICULTADORES }\end{array}$} \\
\hline & 1 & 2 & 3 & \\
\hline [13 - O acesso ao material didático utilizado no curso.] &, 718 & ,462 & , 180 & \multirow{14}{*}{ 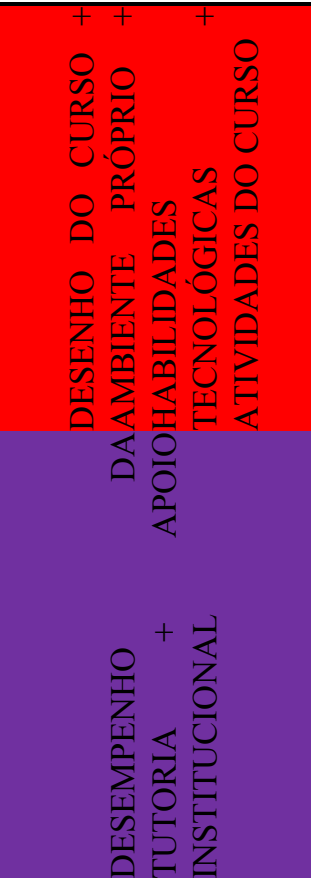 } \\
\hline [17 - Acesso às informações do curso antes do seu início.] & ,705 & ,491 & & \\
\hline [09 - O acesso ao sistema virtual do curso.] & ,702 & ,386 & ,286 & \\
\hline $\begin{array}{l}\text { [20 - O grau de dificuldade das atividades propostas pelo } \\
\text { curso.] }\end{array}$ &, 696 &, 160 & ,365 & \\
\hline $\begin{array}{l}\text { [16 - Minha habilidade em utilizar recursos e ferramentas } \\
\text { tecnológicas do curso.] }\end{array}$ &, 685 & , 162 & ,484 & \\
\hline [19 - Condições do ambiente de estudo em casa.] & ,682 & ,230 & ,468 & \\
\hline [18 - Quantidade de atividades propostas durante o curso.] & ,608 & ,419 &, 191 & \\
\hline [15 - O incentivo familiar para a realização do curso.] &, 563 & ,294 &, 444 & \\
\hline $\begin{array}{l}\text { [01 - O apoio fornecido pelo tutor e interação entre os } \\
\text { participantes do curso.] }\end{array}$ & ,197 & ,812 & ,227 & \\
\hline $\begin{array}{l}\text { [14 - A qualidade do feedback/orientações fornecidos pelo } \\
\text { tutor em relação às minhas participações.] }\end{array}$ & ,202 & ,804 &, 223 & \\
\hline [11 - O vínculo estabelecido entre tutor e alunos.] & ,331 & ,754 &, 194 & \\
\hline $\begin{array}{l}\text { [07 - Apoio da instituição de ensino frente às dificuldades } \\
\text { tecnológicas encontradas por mim durante a realização do } \\
\text { curso.] }\end{array}$ & ,429 & ,708 &, 112 & \\
\hline [03 - A duração total do curso.] & ,462 &, 538 & ,364 & \\
\hline $\begin{array}{l}\text { [06 - A qualidade gramatical das mensagens trocadas pelo } \\
\text { tutor com os alunos.] }\end{array}$ & ,395 &, 533 & ,392 & \\
\hline $\begin{array}{l}\text { [04 - Alterações em minha rotina de trabalho ocorridas durante } \\
\text { a realização do curso.] }\end{array}$ &, 130 & & ,796 & 吕蝗 \\
\hline $\begin{array}{l}\text { [08 - Minha habilidade de conciliar o curso com outras } \\
\text { atividades pessoais.] }\end{array}$ & ,348 & & ,784 & $\sum_{1} \frac{\theta}{x}$ \\
\hline $\begin{array}{l}\text { [02 - Minha habilidade em administrar o tempo para me } \\
\text { dedicar aos estudos.] }\end{array}$ &, 135 & ,353 & ,764 & $\overrightarrow{0}$ \\
\hline $\begin{array}{l}\text { [10 - Minha habilidade de elaborar um plano de estudo que } \\
\text { oriente minhas atividades.] }\end{array}$ & ,305 & ,292 & ,697 & 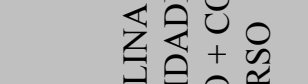 \\
\hline [12 - Eventos familiares durante a realização do curso.] & 391 & 276 & ,506 & \\
\hline [05 - O grau de complexidade do curso.] & ,252 & ,481 & ,489 & 至要是 \\
\hline
\end{tabular}

Fonte: Dados da pesquisa.

Nota: Método de extração: Análise do Componente principal.

Método de rotação: Varimax com normalização de Kaiser.

a. Rotação convergida em 8 iterações.

Comparando-se os resultados, observa-se no Quadro 1, os fatores apontados em ordem de facilidades e dificuldades percebidas.

\begin{tabular}{|c|c|}
\hline Maiores facilidades & Maiores dificuldades \\
\hline $\begin{array}{l}\text { A primeira componente (disciplina e habilidades } \\
\text { gerais do aluno) }+(\text { desenho do curso); } \\
\text { Segunda Componente (desempenho da tutoria) }+ \\
\text { (apoio institucional); } \\
\begin{array}{lll}\text { Terceira componente (ambiente } \quad \text { próprio) } & + \\
\text { (atividades do curso); } & \end{array} \text { - } \\
\text { A quarta componente (complexidade do curso). }\end{array}$ & $\begin{array}{l}\text { A primeira componente (desenho do curso) }+ \\
\text { (habilidades tecnológicas) }+(\text { ambiente próprio) }+ \\
\text { (atividades do curso); } \\
\text { A segunda componente (desempenho da tutoria) }+ \\
\text { (apoio institucional); } \\
\text { A terceira componente (disciplina) }+(\text { habilidades } \\
\text { gerais do aluno) }+(\text { complexidade do curso). }\end{array}$ \\
\hline
\end{tabular}

Quadro 1 Comparação dos resultados.

Fonte: Dados da pesquisa. 


\section{EDUCAÇÃO A DISTÂNCIA: UMA ANÁLISE ESTATÍSTICA DOS FATORES RELACIONADOS À \\ EVASÃO E À PERMANÊNCIA \\ DOI: http://dx.doi.org/10.5007/1983-4535.2016v9n4p26}

Em especial, as dificuldades apontadas concentram-se no (desenho do curso) + (habilidades tecnológicas) + (ambiente próprio) + (atividades do curso), em consonância com os estudos de Abbad, Carvalho e Zerbini (2006); Fernandes et al. (2010); Almeida et al. (2013) e Umekawa (2014).

Percebe-se, através do Quadro 1, que tanto para a tendência a permanecer, quando para a ocorrência de evasão, a dimensão com maior influência foi o desenho do curso. A primeira componente apresenta, além do desenho do curso como fator facilitador, a disciplina e habilidades gerais do aluno como maiores facilitadores da permanência, enquanto que as habilidades tecnológicas, o ambiente próprio e as atividades do curso surgem como os maiores fatores dificultadores, contribuindo significativamente para a evasão.

Observa-se que a segunda componente é a mesma tanto para os alunos matriculados e ou formados quanto para os alunos evadidos, o que leva a inferir que o desempenho da tutoria e o apoio institucional são fatores importantes para a manutenção dos alunos e para a diminuição da evasão desde que estes fatores sejam adequadamente trabalhados no PAP, como se observa em Almeida et al. (2013) e Umekawa (2014).

Como sugestão, o PAP deverá adotar sistemáticas de treinamento para os tutores sobre o desenho dos cursos e as atividades dos cursos, assim como, a utilização de ferramentas com a finalidade de identificar os sinais de dificuldades enfrentadas pelos alunos visando intervenção imediata para resgatar o aluno e, consequentemente, obter uma diminuição da evasão. Para Pacheco et al. (2009, p. 10), quanto maior o desempenho do tutor, menor será o índice de alunos evadidos, ressaltando a importância de um sistema de acompanhamento (tutoria) adequado e supervisionado, com avaliação periódica desse sistema, através de uma avaliação de desempenho dos tutores.

\section{CONCLUSÕES E CONSIDERAÇÕES FINAIS}

Em decorrência do aumento da demanda por ações educacionais ofertadas na modalidade a distância é primordial promover a avaliação constante da efetividade de tais ações ofertadas para um grande número de pessoas, visando garantir que os objetivos de aprendizagem inicialmente propostos sejam alcançados.

A Análise Fatorial aplicada forneceu indícios de que quanto mais forem adotadas medidas de aprendizagem, maiores serão as possibilidades de o alunado perceber um conjunto de variáveis como influenciador sobre sua permanência ou evasão do curso. 


\section{EDUCAÇÃO A DISTÂNCIA: UMA ANÁLISE ESTATÍSTICA DOS FATORES RELACIONADOS À

Portanto, dentre os alunos que permaneceram matriculados ou estão formados, as componentes que se apresentaram como maiores facilitadoras são: primeira componente, composta de 08 (oito) questões, retrata a (disciplina e habilidades gerais do aluno) + (desenho do curso); segunda componente, composta de 06 (seis) questões, retrata o (desempenho da tutoria) + (apoio institucional); terceira componente, composta de 05 (cinco) questões, retrata o (ambiente próprio) + (atividades do curso) e a quarta componente, representada por apenas 01 (uma) questão, retrata a (complexidade do curso), explicadas por 61,56\% da variância total dos dados.

Para os alunos evadidos, as componentes que se apresentaram como maiores dificultadoras são: primeira componente é formada de 08 (oito) questões, retrata o (desenho do curso $)+$ (ambiente próprio) + (habilidades tecnológicas) + (atividades do curso); a segunda componente, composta de 06 (seis) questões, retrata o (desempenho da tutoria) + (apoio institucional) e a terceira componente, composta de 06 (seis) questões, retrata a (disciplina) + (habilidade do aluno) + (complexidade do curso), explicadas por $67,27 \%$ da variância total dos dados, valor um pouco superior, se comparado à variância explicada retratada no grupo de alunos matriculados e alunos formados.

As dificuldades apontadas, em especial, concentram-se no desenho curso, ambiente próprio, habilidades tecnológicas do aluno e atividades do curso.

Vale ressaltar que o desempenho do tutor e o apoio institucional aparecem como segunda componente tanto para os alunos matriculados e formados quanto para os alunos evadidos. Portanto, o levantamento destes fatores pode servir de subsídio para reflexões sobre o perfil dos alunos que buscam sua formação através da EaD.

O presente estudo apresenta como limitação o fato da pesquisa ter sido realizada em apenas um polo de EaD o que impossibilita a generalização dos resultados para outros polos e também para outras instituições que adotam essa modalidade de ensino. Como sugestões para estudos futuros, citam-se a ampliação da pesquisa para outros polos e para outras instituições que utilizam a modalidade em EaD.

Propõe-se, também, o aprofundamento do entendimento dos fatores que mais impactam a permanência ou evasão dos alunos de $\mathrm{EaD}$, favorecendo ou dificultando a participação nos cursos. Com base nos resultados obtidos neste estudo e a limitação da pesquisa, estudos adicionais serão necessários. 


\section{REFERÊNCIAS}

ABBAD, Gardênia; CARVALHO, Renata Silveira; ZERBINI, Thaís. Evasão em curso via Internet: explorando variáveis explicativas. RAE-eletrônica, v. 5, n. 2, p.1-16, jul./dez. 2006.

ALMEIDA, Onília Cristina de Souza de, ABBAD, Gardênia, MENESES, Pedro Paulo Murce, ZERBINI, Thaís. Evasão em Cursos a Distância: Fatores Influenciadores. Revista Brasileira de Orientação Profissional, v. 14, n. 1, p. 19-33, jan./jun. 2013.

CORRAR, Luiz J. Paulo, Edilson.José Maria Dias Filho. Análise Multivariada: para Cursos de Administração, Ciências Contábeis e Economia. São Paulo: Atlas, 2007. 568 p.

COSTA, Priscila Berenice; PRADO, Cláudia; DE OLIVEIRA, Luciana de Fátima Teixeira; PERES, Heloisa Helena Ciqueto; MASSAROLLO, Maria Cristina Komatsu Braga; FERNANDES, Maria de Fátima Prado; LEITE, Maria Madalena Januário; FREITAS, Genival Fernandes de. Fluência digital e uso de ambientes virtuais: caracterização de alunos de enfermagem. Revista da Escola de Enfermagem da USP, v. 45, n. spe, p. 1589-1594, out./nov. 2011.

DE FÁTIMA BRUNO-FARIA, Maria; FRANCO, Angélica Lopes. Causas da evasão em curso de graduação a distância em Administração em uma universidade publica federal.

Teoria e Prática da Educação, v. 14, n. 3, p. 43-56, 2012.

FERNANDES, Jocimar; FERREIRA, Ailton da Silva; NASCIMENTO, Denise Cristina de Oliveira; SHIMODA, Eduardo; TEIXEIRA, Giovany Frossard. Identificação de Fatores que Influenciam na Evasão em um Curso Superior de Ensino a Distância. PerspectivasOnLine 2007-2010, v. 4, n. 16, p. 80-91, 2010.

FERRUGINI, Lílian; SOUZA, Donizeti Leandro de; MORAIS, Raphael; PINTO, Cintia Loos. Educação a Distância no Brasil: potencialidades e fragilidades. Revista da Universidade Vale do Rio Verde, v. 12, n. 1, p. 90-98, jan./jul. 2014.

FIUZA, Patrícia Jantsch, SARRIERA, Jorge Castellá. Motivos para Adesão e Permanência Discente na Educação Superior a Distância. Psicologia Ciência e Profissão, v. 33, n. 4, p. 884-901, 2013.

GARCIA SOBREIRA, Henrique; LEROUX, Liliane; SAMPAIO, Leonardo Lima; BASTOS, Felype Lopes; SILVA, Rodrigo Mesquita da. Inovação tecnológica na área de Educação em contexto de disseminação tecnológica-a experiência da Pós-Graduação em Educação, Cultura e Comunicação nas Periferias Urbanas-FEBF/Uerj. Revista Brasileira de Pós-Graduação, v. 10, n. 20, p. 395-419, 2013.

HAIR, Joseph F;.ANDERSON, RE; TATHAM, WC. Análise Multivariada de Dados. 5. ed. Porto Alegre: Bookman, 2005. 593 p.

HAIR, Joseph F;.ANDERSON, RE; TATHAM, WC. Análise Multivariada de Dados. 6. ed. Porto Alegre: Bookman, 2009. 688 p. 
LAKATOS, Eva Maria; MARCONI, Marina de Andrade. Fundamentos de Metodologia Científica. 7. ed. São Paulo: Atlas, 2010. 320 p.

PACHECO, Andressa Sasaki Vasques; MELO, Pedro Antônio de; TOSTA, Kelly Cristina Benetti Tonani; NAKAYAMA, Marina Keiko; RISSI, Maurício; FREIRE, Patrícia de Sá; SOARES, Aline Pereira. Características da evasão dos estudantes do projeto piloto do curso de administração a distância da UFSC. Novas Tecnologias na Educação, v. 7, n. 3, p. 84-94, dez. 2009.

SALVUCCI, Mara; LISBOA, Marcos J. A.; MENDES, Nelson C. Educação a distância no Brasil: fundamentos legais e implementação. Associação Brasileira de Educação a Distância, v. 11, p. 49-62, 2012.

SILVA, Andréa Soares Rocha da; ANDRIOLA, Wagner Bandeira. Uso de equações estruturais para validar um modelo explicativo da relação entre domínio tecnológico, interação e aprendizagem colaborativa na Educação a Distância (EaD). Ensaio: aval. pol. públ. Educ., v. 20, n. 75, p. 373-396, abr./jun. 2012.

UMEKAWA, Elienay Eiko Rodrigues. Preditores de fatores relacionados à evasão e à persistência discente em ações educacionais a distância. 2014. 256 f. Dissertação (Mestrado em Ciências) - Faculdade de Filosofia Ciências e Letras, USP Ribeirão Preto, 2014. 